\title{
Economic Analysis of Supply Response in Pakistan's Agriculture
}

\section{Muhammad Ali Chaudhary ${ }^{*}$}

\begin{abstract}
This study represents an attempt at estimating the farmer supply response to different economic and material incentives. Several researchers have estimated the cultivator supply response to different techno-economic factors (Cummings, $1975 \mathrm{a}$ and $1975 \mathrm{~b}$; Askari and Cummings, 1977; Cooley, 1973; Chen, Courteny and Schmitz, 1972; Ghosha1, 1975; Tweeten, 1986). However, as agriculture modernises, the relative significance of different factors affecting farm inputs and outputs changes; factors regarded as significant determinants of farmer decision at one time may not be relevant at another time. Similarly, the transformation of agriculture in the desirable direction invariably necessitates and at times renders desirable the use of new measures and policy instruments. How farmers react to changes in market forces and government measures is important to know in different ways. In fact, policy makers are interested in knowing the appropriateness, effectiveness and impact of measures for the ultimate formation or legislation of farm regulations.
\end{abstract}

Farmer supply responsiveness to changes in different factors may be ascertained from changes they introduce in their cropped area, cropping pattern, crop rotations, output, etc. Although the supply responsiveness of farmers may be measured from changes in any of these aspects of farming, this study has analysed the peasant supply response to price and non-price factors with respect to the allocation of the cultivated area among crops of wheat, cotton, rice, sugarcane and maize. Farmers in Pakistan grow some other crops as well. However, the crops considered for this analysis account for the major proportion, 68 per cent, of the cropped area and over 90 per cent of value added of all major crops raised in the country. As such, this study has measured the area allocated to these crops by farmers in response to changes in different factors considered for analysis.

\footnotetext{
* Professor of Economics, Quaid-i-Azam University, Islamabad. The author is extremely thankful to Mr. Anjum Majeed for computer estimation of the model.
} 


\section{Analytical Framework}

The farmer supply response has empirically been estimated by following Nerlove's partial adjustment and adaptive expectation mode1 ${ }^{1}$. In the basic Nerlovian model, it is assumed that the area farmers desire to cultivate is a function of the expected price and some other important variables. Researchers have modified and extended the basic model to reflect specific farm and market conditions. In particular, many new variables with their current and lagged values have been included in the model to explain and measure farmer supply response (Pandey and Manocha, 1984; Sangwan, 1985; Mahend, 1970). Further, researchers have experimented with a number of alternate approaches to specification and formulation of the supply response function. For example, French and Mathews (1971) adapted the basic Nerlovian model to analyse the supply response of perennial crops, Marzuch, Weaver and Helmberger (1980) and Lee and Helmberger (1985) formulated the farmer supply response function under changing government farm programmes and policy regimes and Eckstein (1985) has applied a rational expectation model to measure the observed dynamics of agricultural supply. Similarly, Chen (1972) estimated a response function which allowed a greater degree of flexibility in the lag structure than does the Nerlovian partial adjustment model. Further, Cooley (1973) applied an adapted regression model under the assumption that the disturbances are independent, rather inflexible. Nevertheless, the main adaptations relate generally to the inclusion of non-price variables in the original or the modified forms of the basic Nerlovian model (Askari and Cummings, 1977; Cummings, 1975b; Krishna, 1963; Sangwan, 1985). Although researchers have applied sophisticatedly extended specifications of supply response models to improve the predictive ability of the model, adequately deserved attention has still not been given to the expected price variable in measuring the farmer supply response. The price of a given commodity that the farmer expects to prevail in one period has invariably been assumed to be equal to its actual price in the immediate previous period (Askari and Cummings, 1977; Cummings, 1975a; Ghoshal, 1975; Sangwan, 1985). This seems to be followed more as a computational convenience than as a

\footnotetext{
${ }^{1}$ The basic Nerlove's model is as follows:

$\mathrm{A}_{\mathrm{t}}^{*}=\mathrm{a} 0+\mathrm{a} 1 \mathrm{P}_{\mathrm{t}}^{*}+\mathrm{a} 2+\mathrm{u}_{\mathrm{t}}$

$\mathrm{P}_{\mathrm{t}}^{*}=\mathrm{P}_{\mathrm{t}}^{*}-1+\beta\left(\mathrm{P}_{\mathrm{t}}-1-\mathrm{P}_{\mathrm{t}}{ }_{\mathrm{t}}-1\right)$

At $=A t-1+C\left(A_{t}^{*}-1-A_{t}-1\right)$

Where

At $=$ actual area cultivated $\mathrm{t}$ time $\mathrm{t}$,

$\mathrm{A}_{\mathrm{t}}^{*}=$ area desired to be cultivated at time $\mathrm{t}$,

$\mathrm{P}_{\mathrm{t}}=$ actual price at time $\mathrm{t}$,

$\mathrm{P}_{\mathrm{t}}^{*}=$ expected price

$\mathrm{X}_{\mathrm{t}}=$ other variables
} 
theoretically defensible way of identifying the relevant factors affecting the farmers supply response. This study has first generated the time series of the expected prices and then used them along with other relevant variables in estimating the overall model specified in this study. The estimation of the time series of the expected prices used of all crops considered is explained by expressing the basic Nerlovian model in general form as below:

$$
A_{t}^{*}=f\left(X_{t}, P_{t}^{*}\right)
$$

where,

$A_{t}^{*}=$ the area farmers desire to cultivate at time $t$.

$P_{t}^{*}=$ expected price at time $t$.

$X_{t}=$ other variables used

Since $A_{t}^{*}$ and $P_{t}^{*}$ are not directly observable, this function cannot be estimated. However, the hypotheses of the adaptive expectation and the partial adjustment may respectively be used to explain $\mathrm{P}_{t}^{*}$ and the adjustment of $A_{t}$ to $A_{t}^{*}$. The part of the model related to the adaptive expectations part of the model, which states that the change in expectations equals some fraction of last period's forecast error, may symbolically be

$$
\begin{aligned}
& P_{P}^{*}-P_{t-1}^{*}=\beta\left(P_{t-1}-P_{t-1}^{*}\right) \\
& \text { or } \\
& P_{t}^{*}=P_{t-1}^{*}+\beta\left(P_{t-1}-P_{t-1}^{*}\right) \\
& \text { or } \\
& P_{t}^{*}-\beta{\underset{t-1}{P}}^{*}+(1-\beta) \stackrel{P}{t-1}^{*}
\end{aligned}
$$

expressed as follows:

where $\mathrm{P}_{t}^{*}$ represents the expected prices in period $t, \mathrm{P}_{t}$ represents the actual prices during period $t$ and $\beta$ represents the adjustment coefficient. The last expression signifies that the expected price is a weighted sum of the actual and expected price in the last period.

It may be noted that the component of the model on adaptive expectations is convertible into its distributed lag form. Successive substitutions of the lagged values of actual prices result in expressing the expected price as a weighted sum of past and actual prices as depicted below: 


$$
\begin{aligned}
P_{t}^{*} & =\beta\left[P_{t_{-1}}+(1-\beta) \underset{i_{t}}{P_{t_{1}-2}}+(1-\beta)^{2} P_{t-3}+\ldots .\right] \\
& =\beta \sum_{i=1}^{P_{n}}(1-\beta){\underset{t-1}{P}}^{P}+\ldots
\end{aligned}
$$

The estimation of the expected prices as appears from Eq (3), requires the determination of weights. The required weights depend on the adjustment coefficient, $\beta, \mathrm{P}_{\mathrm{t}}^{*}$ is not directly observable. It is estimated by following such a procedure as minimises expected losses from forecast errors. This is accomplished by estimating $\beta$ from the following quadratic function:

$L=\sum_{i=1}^{n}\left(P_{t}-P_{t}^{*}\right)^{2}$
$=\sum_{i=1}^{n}\left[\begin{array}{lll}P_{t}-\beta \sum_{i=1}^{n} & (1-\beta)^{i-1} & P_{t-i}\end{array}\right]^{2}$

The terms in the function may be restricted to a number after which the inclusion of higher lags does not improve the explanatory power of the model. Usually, restricting the terms to 3 suffices. Restricting the terms to 3 and searching the parameters space from 0 to 1 in interval, the value of $\beta$ may be obtained as below:

$\operatorname{Min} L=\sum_{i=1}^{n} \quad\left[\begin{array}{l}P \\ t\end{array}-\beta \sum_{i=1}^{4} \quad(1-\beta)^{i-1}{\underset{t}{P}-1}_{P}\right]^{2}$

By substituting the error minimising value of $\beta$, the time series of the expected price is generated from Eq (3) restricted to three terms. as below:

The partial adjustment part of the model may, in turn, be specified

$$
A t-A t-1=(1-\lambda)\left(A^{*} t-A t-1\right)+u t . .0<\lambda<1
$$

or

$A t-\lambda A t-1=(1-\lambda) A^{*} t+u t$

Incorporating the adaptive expectation equation and then substituting $A_{t}^{*}$ from Eq (6) into Eq (1), a well distributed error is obtained as shown in the following equation ${ }^{2}$ :

$$
(1-\lambda L) A_{t}=(1-\lambda) A_{t}^{*}+u_{t}
$$

where $\mathrm{L}$ is lag operator, which, in turn, gives

\footnotetext{
${ }^{2}$ See Johnston, 1972 and Nugent, 1979 for further explanation.
} 


$$
\begin{aligned}
A_{t} & =(1-\lambda) A_{t}^{*}+(1-\lambda) A_{t-1}^{*}+(1-\lambda)^{2} A_{t-2}^{*} \quad A_{t-2}^{*}+\ldots .+\left(u_{t}-u_{t-1}\right) \\
& =(1-\lambda)\left[A_{t}^{*}+\lambda A_{t-1}^{*}+\lambda 2+--\right]+\left[\begin{array}{ll}
u_{t}+\lambda^{2} u_{t-2} & +\ldots .
\end{array}\right]
\end{aligned}
$$

So that which is the actual area cropped by the farmers is the Koych-weighted combination of current and all previously desired cropped area and the weighted sum of random disturbance terms of the current and all the previous periods.

Substituting Eq (1) into Eq (6) gives the final form of the model to be estimated as below:

$$
\begin{aligned}
& (1-\lambda L) A^{t}=(1-\lambda) f\left(X_{t},{\underset{t}{P}}^{*}\right)+u_{t} \\
& A_{t}=\lambda A_{t_{-}}+(1-\lambda) f\left(X_{t}, P_{t}^{P^{*}}\right)+u_{t}
\end{aligned}
$$

Eq (8) represents variables other than price to be included in the model. There is a need to explain the variables other than price considered for this analysis. Increasing diffusion of modern technologies in the country has prompted the choice and modification of the variables used. Although the increased use of modern technologies has expanded opportunities for bigger profit, they also have significantly increased farming expenditures. Similarly, while the expanded application of modern inputs has increased yields of crops, it has also increased the risk of greater variations in their prices. The modern varieties of crops compete for timely application of adequate quantities of inputs. Farmer efficiency of allocation of available resources to different crops is likely to be affected by a number of factors. Keeping in view all such considerations, the other variables used along with

$$
A t=\lambda A t-1+(1-\lambda) f\left(P^{*} t, Y t-1, G V p, C V y, R s, I t,\right)+u t
$$

prices of crop outputs are as below:

where,

$$
\begin{array}{ll}
A_{t}, A_{t}-1 & =\text { area actually cultivated at time } t \text { and } t-1 \\
P_{t} & =\text { expected price generated as explained above } \\
C V_{p} & =\text { coefficient of variation of Price } \\
C V_{y} & =\text { coefficient of variation of yield } \\
R_{s} & \text { rainfall of the sowing season of the crop concerned in } \\
& \text { millimeters. } \\
I_{t} & \text { irrigated area under all crops in } 1000 \text { acres. }
\end{array}
$$




\section{I =ratio of irrigated area of the crop concerned to the total} irrigated area under all crops.

The time series data from 1960 to 1986 used in this analysis are generally expected to suffer from the existence of autocorrelation and multicollinearity. Cochrane-Orcutt iterative process and Frischs confluence analysis were respectively applied where their existence was detected. Convergence of $\delta$ (rho) to 0.001 was used as a criterion to stop the iterations in the Cochrane-Orcutt method. $\delta$ was found to be efficient in the first autoregressive scheme, $\mathrm{AR}(1)$, as:

$u_{t}=u_{t-1}+e_{t}$. where $e_{t} \approx N(0, \partial)^{2}$

The data on prices, cropped area, rainfall and irrigated area are obtained from relevant official documents such as the Economic Survey and Agricultural Statistics of Pakistan.

\section{Empirical Results and Discussion}

The estimation of the acreage response functions has revealed the existence of logical relationships among the chosen variables. A Table 1 reveals, except for the variable of yield risk, coefficients are generally consistent with prior theoretical expectations. The coefficients and the associated ' $t$ ' statistics show that the variables have a significant effect on area allocation among crops considered for analysis. The high values of the adjusted $\mathrm{R}^{-2}$ and ' $\mathrm{F}$ ' indicate good fit and the overall significance of the supply response functions. More specifically, the lagged dependent variable has been found to highly significantly affect the acreage allocation among crops being considered. The significant effect of the lagged dependent variable may in part be explained by the farmer experience in a certain cropping pattern and the existence of institutional constraints, particularly of irrigation water supply. The prevalence of varied climatic conditions has led the farmers to follow specific cropping patterns in different parts of the country. As a consequence of harsh climatic conditions, irrigation is indispensable for the profitable production of farm crops. Since the expansion of resources like irrigation, which require long-term investment, occurs slowly, the cultivators continue to follow the familiar cropping pattern. Similarly, the output prices expected to prevail in the harvest period have also other significant determinants of the area planted to different crops, though not to the extent of the lagged dependent variable. It seems important to note further that the expected output prices tend to influence the acreage allocation more among the same than the different season crops. This is why the effect of the expected prices has been more 
pronounced in acreage allocation for cotton and sugarcane than for wheat and rice. The effect of the expected prices on acreage allocation among crops also depends on whether they are food or cash crops. Area allocation

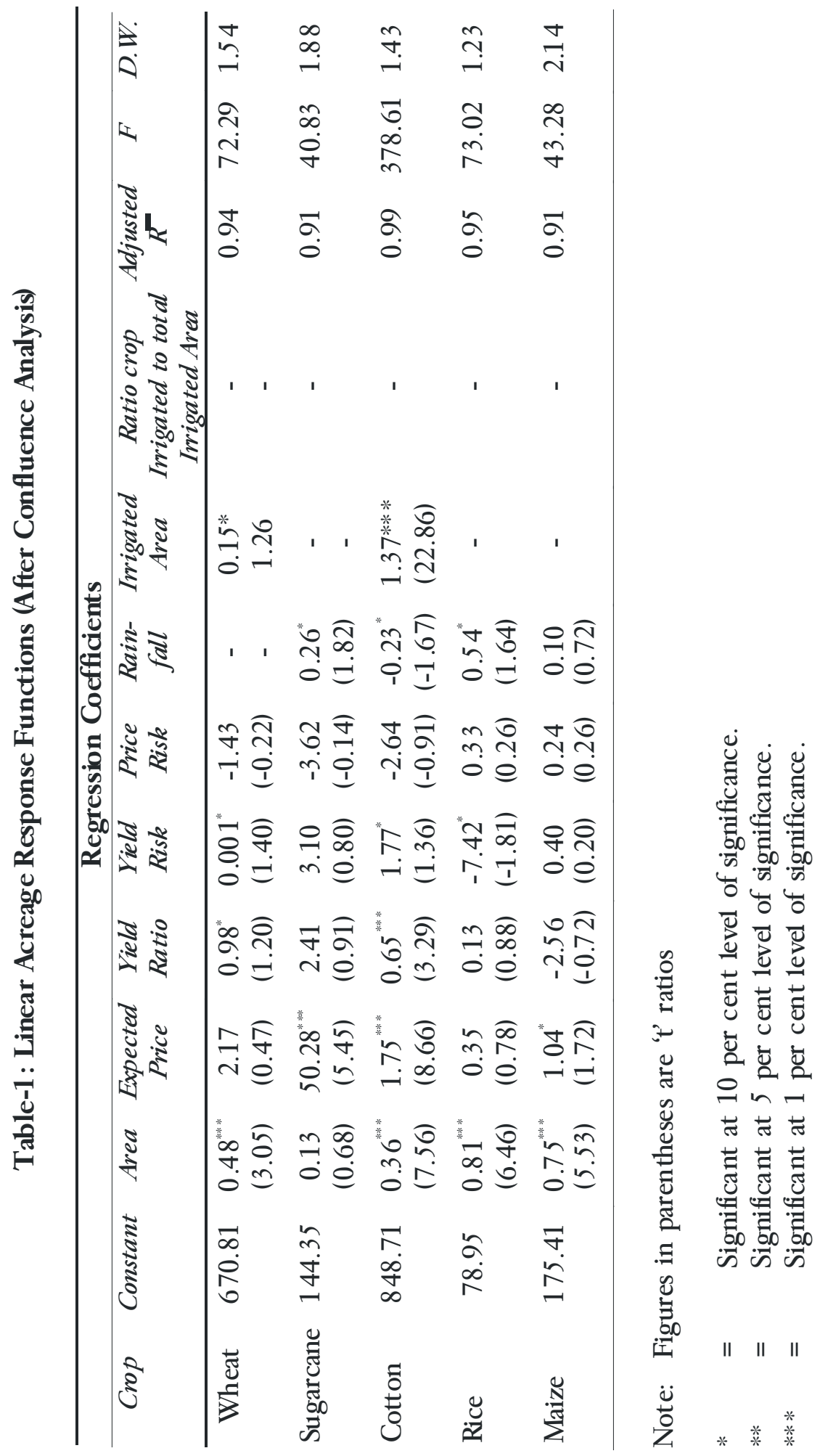


to food crops is in general expected to show less variations compared to that of cash crops. Wheat and, to a lesser extent, rice serve as staple in Pakistan. Thus, farmers especially subsistence farmers have inevitably to put such area under these crops as could enable them to produce food grains commensurate with their family consumption requirements. This implies that area allocation among food crops may not show wide yearly variations. Conversely, the expected prices may lead to relatively more rapid variations in acreage allocation for cash crops of cotton and sugarcane. The farmers raise these crops for the market to ultimately meet financial obligations. Since the requirements of ready cash have in the wake of modern agriculture greatly increased, the expected prices have more significantly affected the farmer supply responsiveness in respect of cash rather than food crops.

Changes in area allocation and cropping pattern involved risk. Generally, such changes give rise to two types of risks, with the first one being associated with variations in yield and the other with fluctuations in prices. How farmers have varied acreage under crops in response to the risks of variations in yield and prices is important to know. The regression results show that the acreage responsiveness has been affected more by yield than price risk. Further, the yield risk has been a more significant determinant of acreage allocation than price risk for cash crops compared to food crops, although wheat acreage has also significantly been affected by the risk of yield variations. More specifically, the increase in yield risk has positively affected area allocated to cotton and wheat whereas it has negatively affected the acreage planted to rice. The existence of the direct (indirect) relationship between yield risk and cropped area of wheat (rice) appears to be consistent with the practical conditions of these crops. In Pakistan, wheat signifies a more important staple and reveals less yield variations than rice. When high yield risk prevails, it results in opposite effects on wheat and rice. The farmers, in pursuance of avoiding shortage of wheat supplies on account of decline in yields, adjust its acreage in response to a decline in its yield to minimise cost of cultivation and probably also to make more acreage available to the following crop of wheat which, has over time become the next important crop for rice fields. The limited time left after harvesting of rice till sowing of wheat constituted a severe constraint and forced many bullock farms to leave rice fields uncultivated for the rest of the year. The introduction of mechanical cultivation has alleviated the constraint of the short interval between harvesting of rice and sowing of wheat and the farmers are now able to accomplish the desired preparation of rice fields for wheat. In this way, the farmers compensate the yield risk induced reduction in rice acreage by increased wheat acreage.

Of the other variables included in the regression functions, irrigated area has been found to significantly affect the farmer acreage responsiveness 
only in wheat and cotton. The effect of irrigated area on area allocation among crops needs to be examined in the light of the total irrigation water availability and crop consumptive water requirements. In principle, the annual acreage of high water delta crops may not show wide variations because their full potential cannot be realised without assured irrigation in adequate quantities. The crops with relatively low consumptive water requirements can, on the other hand, lend themselves for acreage adjustment more readily in response to water availability reflected in the form of total irrigated area in the country. Both wheat and cotton are not only less irrigation-intensive than rice and sugarcane but are also relatively short duration crops. This is probably why farmers have responded differently in terms of adjustment in area allocation among crops. Total irrigated area nationally has positively affected the area planted to both wheat and cotton. Since cropped area with access to irrigation reflects, as mentioned before, the extent of farm water availability, the area under irrigated crops shows a direct correspondence with total irrigated area in the country.

The effect of the supply shifters was also examined by estimating coefficients from non-linear regression functions represented in Table 2. Its comparison with Table 1 shows that the non-linear functions appear to be less superior to the linear functions except for rice in which case the former form of function has yielded more satisfactory estimates. The variables of rainfall, irrigated area and the proportion of rice irrigated area to total irrigated area in the country have been found to be the more significant determinants of area allocated to rice than other variables included in the function. The size of the irrigated area of sugarcane turned significant in the non-linear regression from the insignificant variable in the linear function.

Table 3 depicts the regression coefficients estimated after the data were adjusted for autocorrelation. The removal of autocorrelation has brought about a good improvement in the qualities of the coefficients of irrigated area and that of the ratio of cropped irrigated area to the total irrigated area. However, the lagged dependent variable and yield risk still remained significant determinants of acreage responsiveness in four out of five crops under consideration. Risk associated with prices has also remained, as before, more or less an insignificant determinant of the cultivator supply response. The values of the adjusted $\mathrm{R}^{-2}$ have further increased. In four out of five regression functions, its values are close to 1 which signifies a perfect fit. Similarly, the overall significance of all the functions, as indicated by the ' $F$ ' statistic, has remarkably improved. Although all the functions were overall highly significant when only Frisch's confluence analysis was applied in regressions, their significance has further improved on the use of the Cochrane-Orcutt procedure in removing autocorrelation from the data set analysed. 
10 The Lahore Journal of Economics, Vol.5, No.2

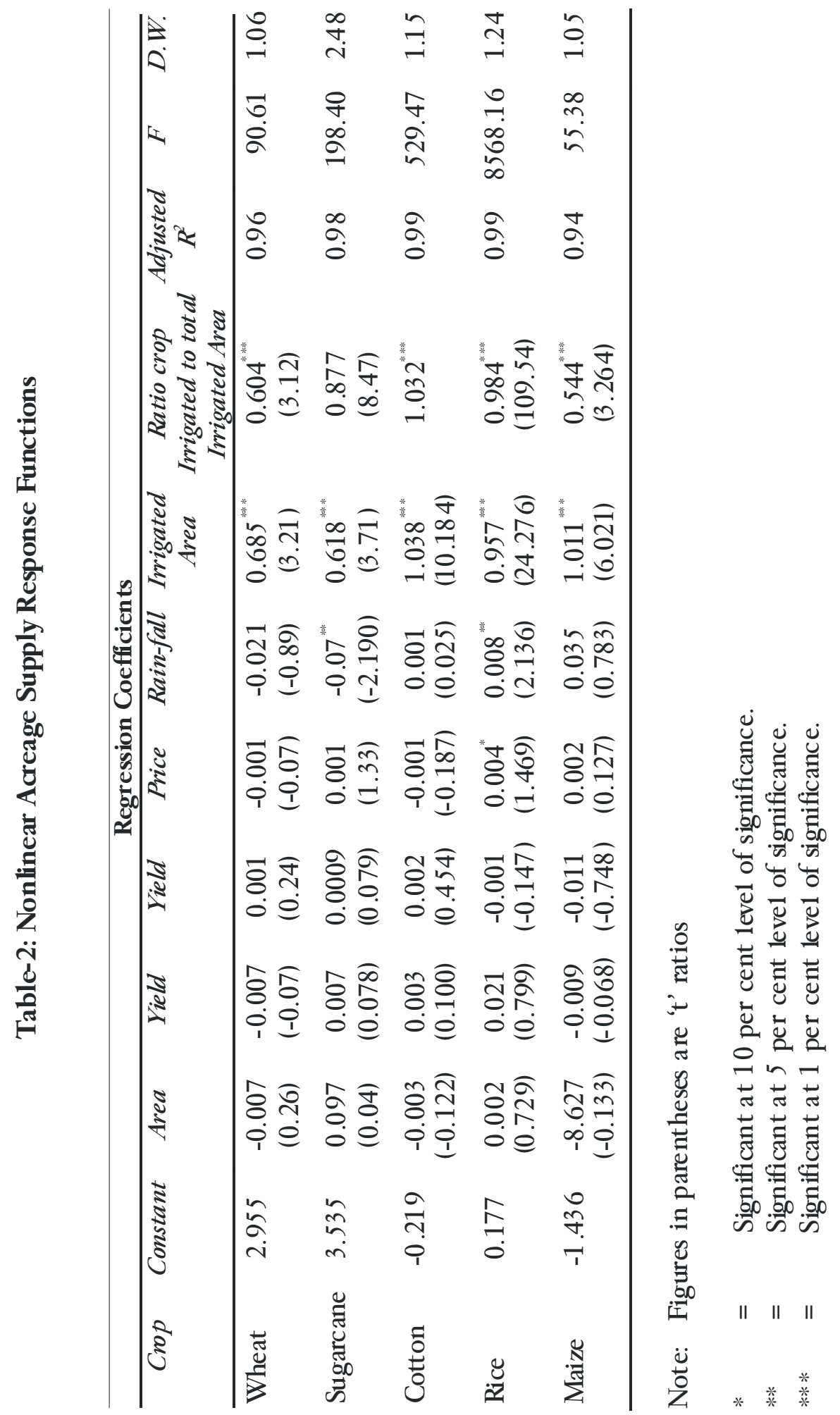




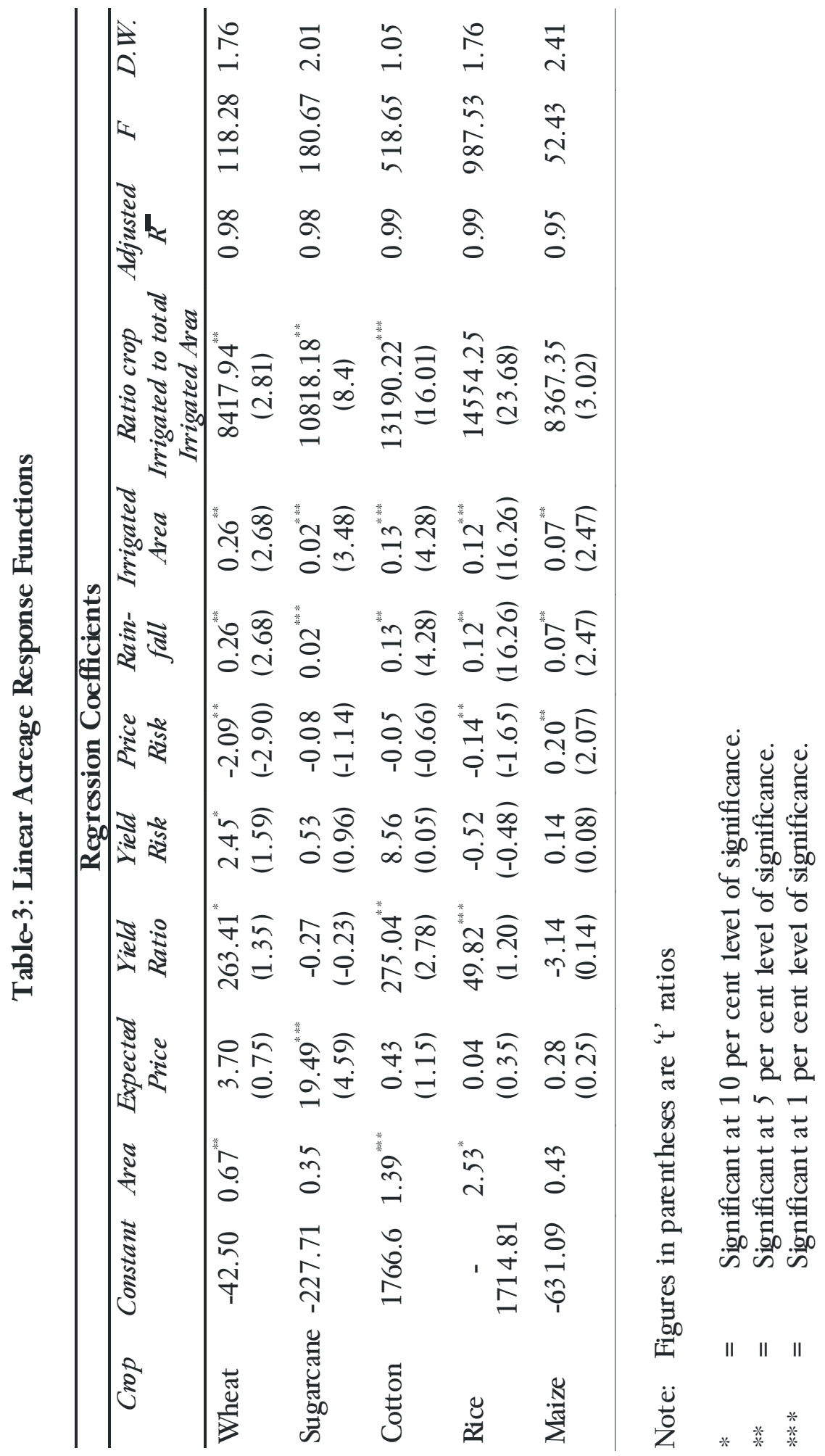




\section{Area Adjustment and Short-Run and Long-Run Elasticities}

To what extent the farmers were able to adjust acreage under different crops in response to expected prices of their products and other supply shifters can be ascertained from Table 3 . If the lagged dependent variable did not enter significantly, the adjustment coefficient for that crop is considered unity i.e. this crop shows full adjustment (Madhavan, 1972). With this in mind, we can judge the acreage adjustment of the crops being analysed. All the adjustment coefficients range from 0.36 for cotton to 0.74 for maize (Table 4). Alternatively, these coefficients show that the maximum adjustment has been achieved in acreage planted to maize and wheat and only moderate adjustment has been shown in the case of the remaining crops.

The short-run and the long-run acreage elasticities with respect to price have been found to be generally low. Although the elasticities are small in size, they are significant in the case of wheat, cotton, sugarcane and maize. Similarly, the elasticity coefficients of acreage with respect to yield have also been found to be significant for rice and cotton. In general, both the short-run and the long-run elasticities estimated in this study are satisfactory. The small size of the elasticities obtained are comfortably comparable with elasticities reported in similar earlier studies. A comparison of our estimates of the elasticities of acreage with respect, in particular, to price with other estimates depicted in Table 5 shows that our estimates for wheat and cotton are close to those obtained by Cummings (1975) and Tweeten (1986). However, both the short-run and the long-run estimates of this study are significantly greater in size than those of any other estimates calculated by other researchers in recent times. Similarly, the elasticity of acreage with respect to yield for sugarcane is close to what has been estimated by Sangwan (1985). 
Muhammad Ali Chaudhary 13

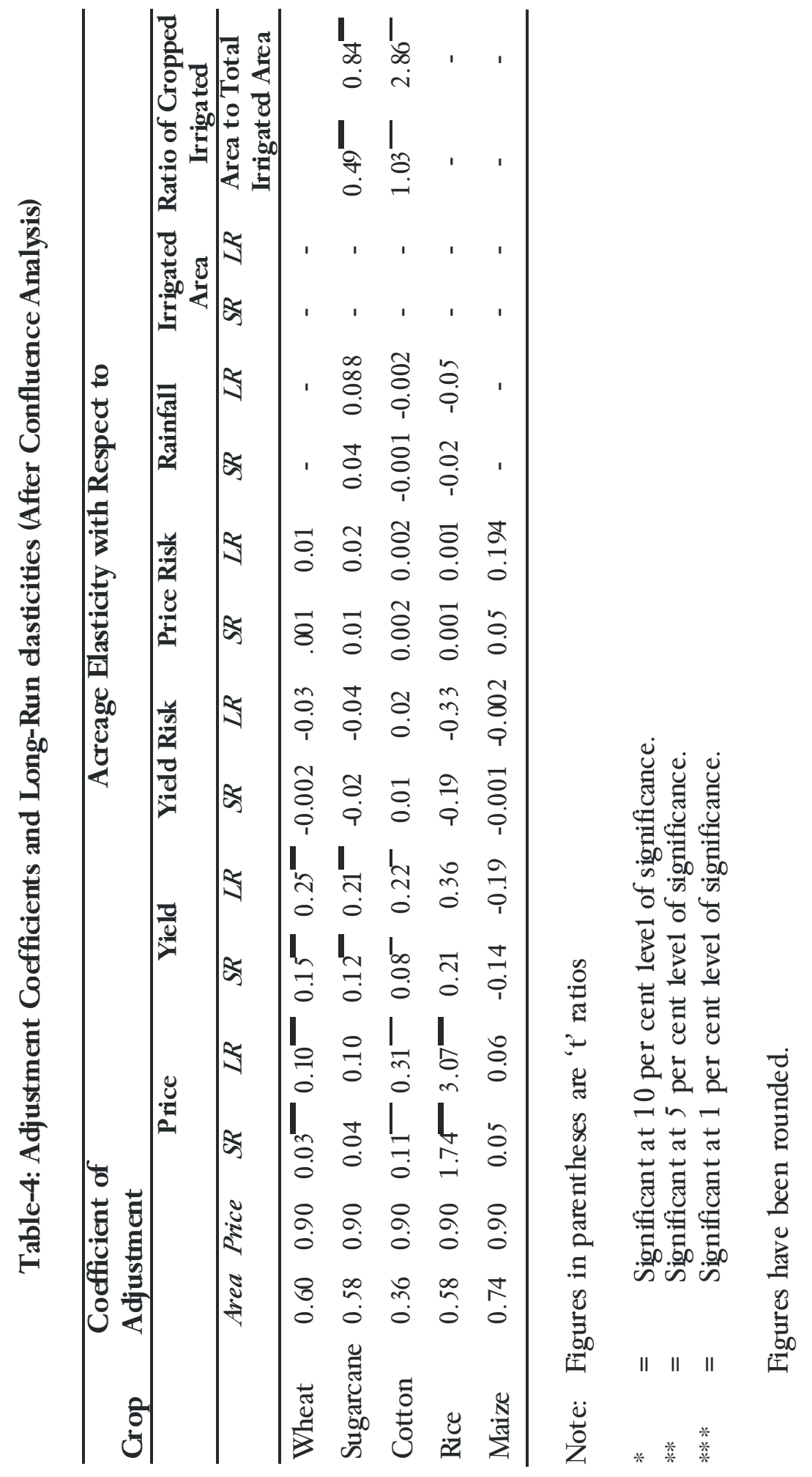


14 The Lahore Journal of Economics, Vol.5, No.2

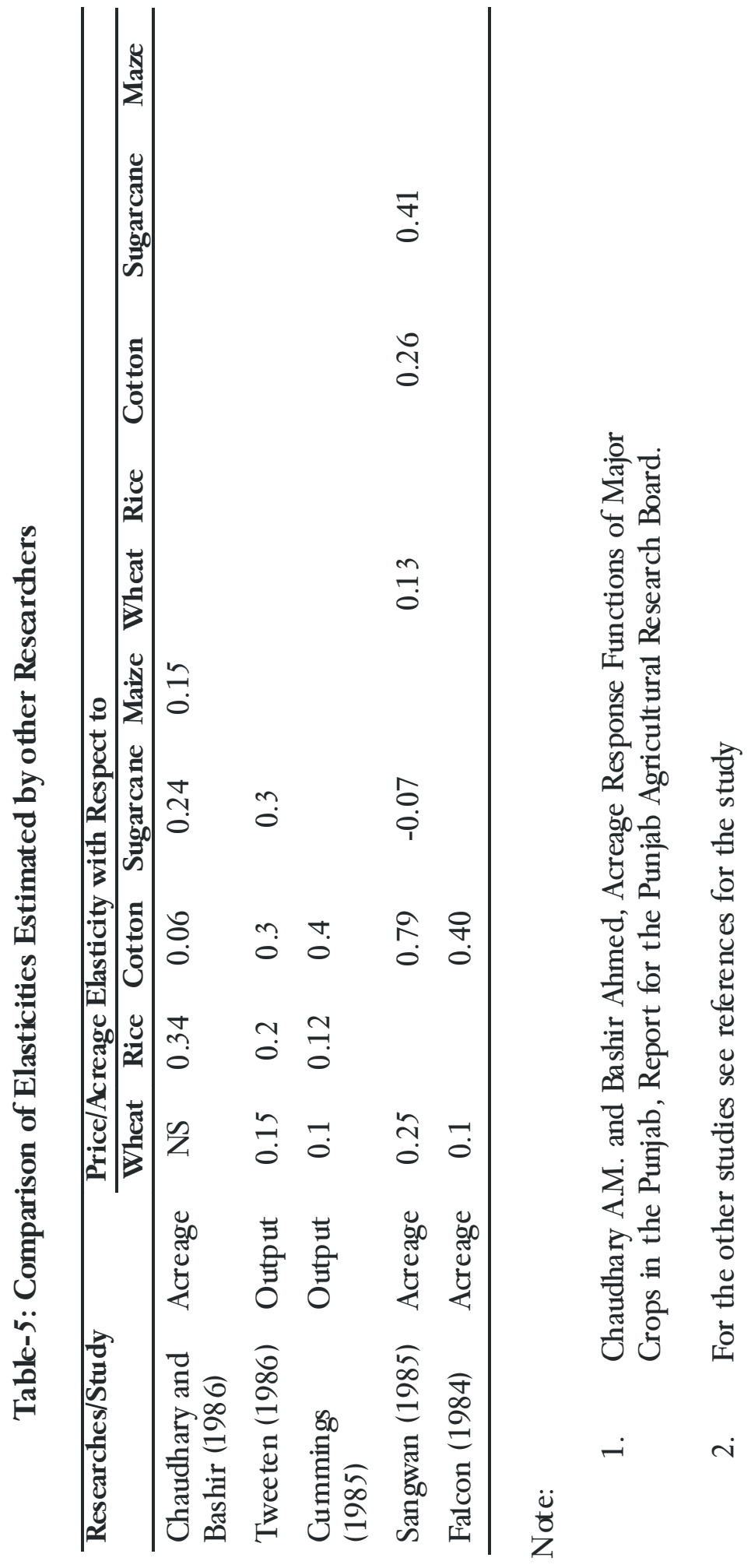




\section{Summary}

The study attempted to examine the farmer acreage responsiveness to price and other supply shifters. The lagged dependent variable has been found to be a significant determinant of acreage under cultivation of nearly all the crops considered for analysis. The expected price and yield variables have been significant determinants in more than half the crops in their area allocation by farmers. It has also been ascertained that the risk in acreage allocation is caused more by variations in yields of crops than by changes in prices. This may be because prices have all the time been moving upwards whereas yields have revealed considerable fluctuations. The statistical estimation of the cultivator supply response has yielded coefficients consistent with theoretical expectations in most of the cases. The short-run and long-run elasticities of acreage with respect to price, yield, risk of yield and certain other supply shifters were found to be generally acceptable on theoretical considerations and comfortably comparable with the estimates calculated in other recent studies.

The main conclusion of the study is that efforts are needed to be made to enable the farmers to achieve stable yields. The significant influence of the lagged dependent variable on acreage allocation also seems to urge for measures conducive for better performance of crops in terms of productivity. 


\section{References}

Askari, Hossein and John Cummings, 1977, "Estimating Agricultural Supply Response with the Nerlove Mode1: A Survey", International Economic Review, Vo1. 18, No. 2, PP. 257-291.

Chen, Dean, Richard Courteny, and Andrew Schmitz, 1972, “A Polynomial Lag Formulation of Milk Production Response", American Journal of Agricultural Economics, Vo1. 54, No. 1, PP. 77-83.

Cooley, Thomas F. and Edward C. Prescott, 1973, "An Adaptive Regression Mode1”, International Economic Review, Vol. 14, No. 2, PP. 364-371.

Cummings, John T. “ The Supply Responsiveness of Bangalee Rice and Cash Crop Cultivators”, The Bangladesh Development Studies.

Cummings, John T. 1975a, “The Supply Responsiveness of Indian Farmers in the Post-Independence Period: Major Cereals and Cash Crops”, Indian Journal of Agricultural Economics, Vo1. XXX, No. 1, PP. 25-40.

Cummings, John T. 1975b, "Cultivator Responsiveness in Pakistan: Cereals and Cash Crops”, Pakistan Development Review, Vo1. XIV, PP. 261-273.

Eckstein, Zvi, 1985, “The Dynamics of Agriculture Supply: A Reconsideration”, American Journal of Agricultural Economics, Vo1. 67, No. 2, PP. 204-212.

Falcon, Walter P. 1964, "Farmer Response to Price in a Subsistence Economy: The Case of West Pakistan”, The American Economic Review, Vo1.54, PP.580-591.

French, Ben C. Jim L. Mathews, 1971, “A Supply Response Mode1 for Perennial Crops”, American Journal of Agricultural Economics, Vo1. 53, No. 3, PP. 478-490.

Gosha1, Animesh, 1975, "The Price Responsiveness of Primary Producers: A Relative Supply Approach”, America Journal of Agricultural Economics, Vol. 57, PP. 116-119.

Hussain, Syed Mushtaq, 1964, "A Note on Farmer Response to Price in East Pakistan”, Pakistan Development Review, Vol. IV, PP. 93-106.

Jhonston, J. 1972, Econometric Methods, $2^{\text {nd }}$ Ed. New York, McGraw Hill Book Company. 
Krishna, Raj, 1963 "Farmer Supply Response in India-Pakistan: A Case Study of the Punjab Region”, The Economic Journal, Vol. LXXIII, No. 29.

Lee, David R. and Peter G. Helmberger, 1985, "Estimating Supply Response in the Presence of Farm Programmes", American Journal of Agricultural Economics, Vo1. 67, No.2, PP. 193-203.

Madhavan, M. C., 1972, "Acreage Response of Indian Farmers: A Case Study of Tamil Nadu”, Indian Journal of Agricultural Economics, Vo1. XXVII, No. 1, PP. 67-86.

Mahend, Reddy J. 1970, "Estimation of Farmers' Supply Response-A Case Study of Groundnuts”, Indian Journal of Agricultural Economics, Vol. XXV, PP. 57-63.

Morzuch, B. J., R. D. Weaver, and P. G. Helmberger, 1980, "Wheat Acreage Supply Response under Changing Farm Programmes American Journal of Agricultural Economics, Vo1. 62, No. 1, PP. 29-37.

Nerlove, Marc, 1958, The Economics of Supply: Estimation of Farmer Supply Response to Price, John Hopkins University Press, Baltimore.

Nugent, Jaffrey B. and Constantine Glezakos, 1979, "A Model of Inflation and Expectations in Latin America”, Journal of Development Economics, Vo1. 6, No. 3, PP. 431-446.

Pandey, U. K., P. K. Sardana and Veena Manocha, 1984, "An Estimate of Demand for and Supply of Cereals, Coarse Grains, Pulses and Oilseeds in Haryana", Indian Journal of Agricultural Economics, Vol. XXXIX, Vo1. 1, PP. 84-99.

Sangwan, S. S. 1985, “ Dynamics of Cropping Pattern in Haryana : A Supply Response Analysis”, The Developing Economies, Vol. XXIII, No. 2, PP. 173-185.

Sidhu, Surjit S. and Carlos A. Baanante, 1981, “ Estimating Farm Leve1 Input Demand and Wheat Supply in the Indian Punjab Using a Translog Profit Function”, American Journal of Agricultural Economics, Vol. 63, No. 2, PP. 237-246.

Sherwani, Vahid, 1968, Agricultural Supply in India: Some Theoretical and Empirical Studies, Ph. D. Thesis.

Tweeten, L. 1968, Supply Response in Pakistan: Report for the Agricultural Policy Analysis Project, USAID, Washington D. C. 